\title{
Assessment of hydrological processes in a small watershed using SWAT
}

\author{
V. Tejaswini and K. K. Sathian
}

Received : 29.12.2017; Revised : 06.02.2018; Accepted : 15.02.2018

See end of the Paper for authors' affiliation

Correspondence to :

V. Tejaswini

Department of Land and Water Resources

Conservation Engineering, Kelappaji College of Agricultural Engineering and Technology, Tavanur, Malappuram (Kerala) India

Email : vallutejaswini@ gmail.com
ABSTRACT : Water availability is declining and the demand is increasing, leaving the gap between these two more wide day by day. Quantifying the elements of hydrologic processes at micro watershed scale and at weekly or monthly temporal scale is the prerequisite for water resources development of a locality. Hydrologic modeling is a very powerful technique in planning water resources of a locality. Valancheri watershed, which is a sub basin of Bharathapuzha river basin, Kerala is taken for the study. As the study watershed is ungauged one, calibration was done for Kunthipuzha basin which is having similar characteristics with the study area and the calibrated parameters were transferred to the study watershed (Regionalization technique). The model was calibrated for the period 2000-2006 and validated for 2007-2009. Performance of the model was satisfactory with NSE $=0.81, \mathrm{R}^{2}=0.82$ for calibration period and $\mathrm{R}^{2}=0.95, \mathrm{NSE}=0.82$ for validation period. The calibrated model was used to predict the hydrologic elements of the Valancheri watershed at micro watershed level. The simulation results were great use in planning water resources development of the locality.

- KEY WORDS : Watershed model, SWAT, ArcGIS, Hydrological response units, Water balance components

-HOW TO CITE THIS PAPER : Tejaswini, V. and Sathian, K.K. (2018). Assessment of hydrological processes in a small watershed using SWAT. Internat. J. Agric. Engg., 11(1) : 41-48, DOI: 10.15740/ HAS/IJAE/11.1/41-48. 